\title{
Likuiditas, Profitabilitas dan Struktur Modal Terhadap Nilai Perusahaan dengan Variabel Moderasi CSR
}

\author{
Hannawanti*, Eduard Ary Binsar Naibaho \\ Fakultas Ekonomi dan Bisnis, Program Studi Akuntansi, Universitas Pelita Harapan, Jakarta, Indonesia \\ Email: 1,"Hannawanti@gmail.com, ${ }^{2}$ eduard.naibaho@uph.edu \\ Email Penulis Korespondensi: Hannawanti@gmail.com \\ Submitted: 20/11/2021; Accepted: 28/11/2021; Published: 30/11/2021
}

\begin{abstract}
Abstrak-Nilai perusahaan adalah tujuan utama setiap perusahaan. Penelitian ini menguji hubungan dari likuiditas, profitabilitas, dan struktur modal terhadap nilai perusahaan dan menggunakan Corporate Social Responsibility sebagai variabel moderasi. Likuiditas diukur menggunakan Current Ratio, profitabilitas diukur menggunakan Return On Asset, struktur modal diukur menggunakan Debt to Equity Ratio, nilai perusahaan diukur menggunakan Tobin's $Q$ dan CSR menggunakan indikator CSR Global Reporting Initiative versi G4. Data observasi pada penelitian ini sebanyak 240 data dari perusahaan konsumen non primer yang terdaftar di Bursa Efek Indonesia pada tahun 2010-2019. Penelitian ini menggunakan data sekunder dari S\&P Capital IQ dan laporan keuangan perusahaan. Hasil penelitian ini menunjukan bahwa likuiditas memiliki arah positif namun tidak berpengaruh signifikan terhadap nilai perusahaan, profitabilitas memiliki arah positif dan berpengaruh signifikan terhadap nilai perusahaan, struktur modal memiliki arah negatif namun berpengaruh signifikan terhadap nilai perusahaan, CSR sebagai variabel moderasi memperlemah hubungan negatif antara likuiditas dengan nilai perusahaan, CSR sebagai variabel moderasi memperlemah hubungan positif antara profitabilitas dengan nilai perusahaan, dan CSR sebagai variabel moderasi memperkuat hubungan positif antara struktur modal dengan nilai perusahaan.
\end{abstract}

Kata Kunci: Corporate Social Responsibility; Likuiditas; Nilai Perusahaan; Profitabilitas; Struktur Modal.

Abstract-Corporate value is the main goal of every company. This study examines the relationship of liquidity, profitability, and capital structure to firm value and uses Corporate Social Responsibility as a moderating variable. Liquidity was measured using the Current Ratio, profitability was measured using Return On Assets, capital structure was measured using the Debt to Equity Ratio, firm value was measured using Tobin's Q and CSR using the G4 version of the CSR Global Reporting Initiative indicator. The observation data in this study were 240 data from non-primary consumer companies listed on the Indonesia Stock Exchange in 2010-2019. This study uses secondary data from S\&P Capital IQ and company financial statements. The results of this study indicate that liquidity has a positive direction but has no significant effect on firm value, profitability has a positive direction and has a significant effect on firm value, capital structure has a negative direction but has a significant effect on firm value, CSR as a moderating variable weakens the negative relationship between liquidity and firm value. firm value, CSR as a moderating variable weakens the positive relationship between profitability and firm value, and CSR as a moderating variable strengthens the positive relationship between capital structure and firm value.

Keywords: Corporate Social Responsibility; Firm Value; Liquidity; Profitability; Capital Structure

\section{PENDAHULUAN}

Pertumbuhan ekonomi Indonesia dapat dilihat melalui Gross Domestic Product (GDP). Berdasarkan data world bank (2021) menunjukkan pertumbuhan GDP Indonesia dari tahun 2010-2019 menunjukkan bahwa Indonesia memiliki tingkat pertumbuhan dengan trend menurun membuat perusahaan harus memiliki daya saing lebih di era kompetitif saat ini. Salah satu caranya dengan memiliki competitive advantage. Competitive advantage dapat meningkatkan daya saing perusahaan dalam mencapai tujuan perusahaan yaitu optimalisasi nilai perusahaan (Jihadi et al., 2021). Nilai perusahaan adalah cara investor untuk menilai suatu perusahaan secara keseluruhan yang dicerminkan melalui harga saham perusahaan. Semakin meningkat harga saham turut meningkatkan nilai perusahaan sehingga membuat pemegang saham semakin makmur (Sukmawardini \& Ardiansari, 2018).

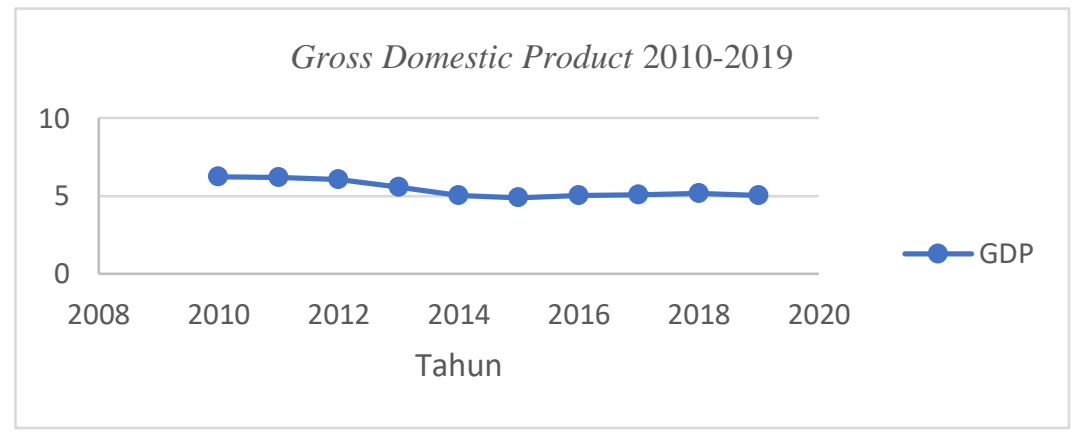

Gambar 1. Pertumbuhan GDP (2010-2019)

Nilai perusahaan terefleksikan dalam pengukuran Tobin's Q, Tobin's Q digunakan untuk mengetahui nilai kapitalisasi pasar dengan nilai buku ekuitas dan nilai buku utang (Marantika, 2012). Nilai perusahaan dipengaruhi oleh berbagai faktor diantaranya likuiditias, profitabilitas, struktur modal, dan lainnya. Nilai likuiditas perusahaan menunjukan kemampuan perusahaan dalam memenuhi kewajiban jangka pendeknya. Hasil penelitian Jariah (2016), menjelaskan 
bahwa semakin tinggi nilai likuiditas yang dimiliki suatu perusahaan maka akan meningkatkan nilai perusahaan. Faktor lain yang mempengaruhi nilai perusahaan adalah profitabilitas. Perusahaan yang memperoleh keuntungan menunjukkan prospek perusahaan yang baik (Ramdhonah et al., 2019).

Nilai profitabilitas yang tinggi menunjukkan kemampuan manajemen perusahaan dalam mengelola operasional dan mengambil keputusan yang tepat untuk perusahaan. Berdasarkan teori Pecking Order, perusahaan cenderung memilih pengambilan pendanaan dari internal dibandingkan eksternal karena dapat memperoleh keuntungan yang lebih tinggi dengan tingkat utang yang kecil. Oleh sebab itu, pengambilan keputusan terkait proporsi antara utang dan modal sangat penting untuk memaksimalkan struktur modal hingga akhirnya dapat meningkatkan nilai perusahaan (Dhani \& Utama, 2017). Salah satu peran perusahaan adalah berkontribusi pada kegiatan ekonomi, namun seiring perkembangan zaman perusahaan tidak hanya bertanggung jawab pada kegiatan ekonomi tapi juga tanggung jawab sosial dan lingkungan (Ruroh \& Latifah, 2018). The Organization for Economic Cooperation and Development (OECD) mengatakan bahwa kontribusi bisnis pada perilaku perusahaan tidak hanya memastikan pengembalian keuntungan pada pemegang kepentingan tapi juga harus merespon nilai sosial dan lingkungan (Kartini, 2020).

Berdasarkan implementasi Corporate Social Responsibility (CSR) dapat diketahui perusahaan yang memiliki keseimbangan antara ekonomi, lingkungan dan sosial sejalan dengan pemenuhan harapan dari pemegang saham (Jihadi et al., 2021). Hasil penelitian Jihadi (2021) menjelaskan bahwa CSR memiliki kemampuan dalam memoderasi pengaruh likuiditas, leverage, dan profitabilitas terhadap nilai perusahaan. Penelitian tersebut juga di dukung oleh penelitian Siregar et al. (2018) dan Mufidah dan Purnamasari (2018) yang menunjukan bahwa CSR dapat memoderasi hubungan antara nilai perusahaan dengan faktor-faktor yang mempengaruhinya sehingga CSR dapat digunakan sebagai variabel moderasi. Tetapi hasil penelitian Siregar et al. (2018) menunjukan CSR tidak dapat memoderasi profitabilitas yang di proksikan dengan menggunakan Return on Asset terhadap nilai perusahaan. Penelitian ini merupakan replikasi dari penelitian Jihadi et al (2021), hal utama yang membedakan penelitian ini dengan penelitian sebelumnya adalah penambahan variabel kontribusi Growth yang diambil dari penelitian Dhani dan Utama (2017). Di sisi lain, peneliti juga menggunakan sampel yang berbeda yaitu perusahaan industri konsumen non primer yang terdaftar di Bursa Efek Indonesia dan periode penelitian tahun 2010-2019 dalam penelitian ini.

\section{METODE PENELITIAN}

\subsection{Kerangka Dasar Penelitian}

Kerangka pemikiran pada penelitian ini menjelaskan mengenai pengaruh hubungan likuiditas, profitabilitas, dan struktur modal terhadap nilai perusahaan dengan variabel moderasi CSR, sebagai berikut :

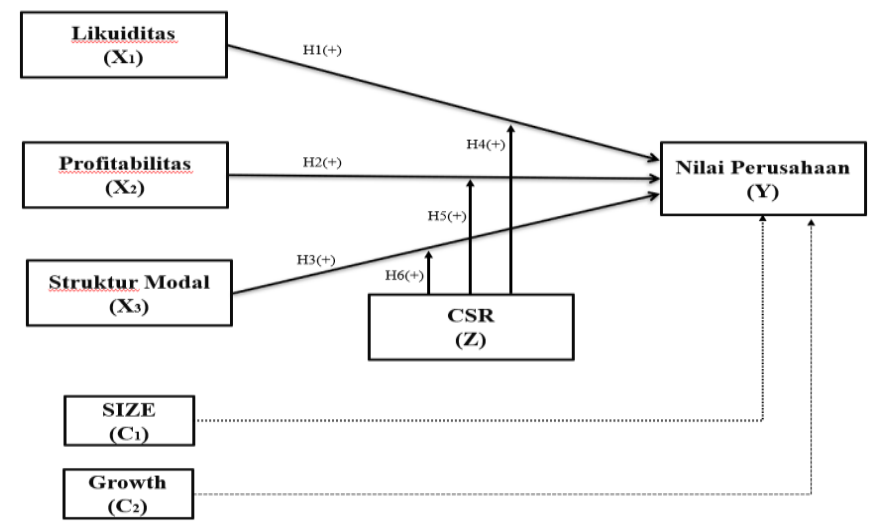

Gambar 2. Kerangka Teoritikal

\subsection{Pengembangan Hipotesis}

\section{a. Pengaruh Likuiditas terhadap nilai perusahaan}

Likuiditas dapat digunakan untuk mengukur kemampuan perusahaan dalam memenuhi kewajiban perusahaan pada saat ditagih (Kasmir, 2017). Tingkat likuiditas yang tinggi menunjukan kemampuan perusahaan dalam membagikan dividen sehingga memberikan sinyal positif untuk investor dalam melakukan keputusan investasi. Sebaliknya saat likuiditas perusahaan rendah hal tersebut menunjukan sedikitnya kas yang tersedia sehingga dapat mempengaruhi nilai dividen yang dibagikan kepada investor. Hal ini akan mempengaruhi investor dalam melakukan pengambilan keputusan investasi pada suatu perusahaan yang turut mempengaruhi nilai perusahaan tersebut. Pada penelitian Jihadi et al. (2021) dijelaskan bahwa likuiditas mempunyai pengaruh positif terhadap nilai perusahaan. Berdasarkan nilai likuiditas dapat memberikan informasi kepada investor, cara suatu perusahaan dalam memaksimalkan nilai aset sehingga dapat memenuhi kewajiban membayar utang lancar sehingga investor dapat mempertimbangkan keputusan berinvestasi. Berdasarkan uraian di atas penelitian ini mengajukan hipotesa sebagai berikut:

H1 : Likuiditas berpengaruh positif terhadap nilai perusahaan 


\section{b. Pengaruh profitabilitas terhadap nilai perusahaan}

Profitabilitas digunakan untuk mengukur kemampuan perusahaan dalam memperoleh laba pada suatu periode waktu tertentu (Kasmir, 2017). Berdasarkan teori signal, dijelaskan bahwa saat perusahaan mengalami keuntungan maka akan memberikan sinyal positif kepada investor karena perusahaan dinilai telah mempunyai kinerja yang baik. Sedangkan jika perusahaan mengalami kerugian akan memberikan sinyal negatif dan menunjukkan kinerja yang tidak baik. Profitabilitas yang tinggi juga menunjukkan prospek perusahaan kedepannya sehingga menarik investor untuk melakukan investasi sehingga dapat meningkatkan nilai perusahaan yang tercermin pada harga saham perusahaan.

Profitabilitas dalam penelitian Dhani dan Utama (2017) menunjukan bahwa profitabilitas memiliki pengaruh positif dan signifikan terhadap nilai perusahaan. Hasil tersebut menunjukan profitabilitas akan memicu investor untuk melakukan investasi pada suatu perusahaan dengan meningkatnya permintaan saham dari investor akan membuat nilai perusahaan juga meningkat. Penelitian tersebut sejalan dengan penelitian Jihadi et al. (2021), Mufidah dan Purnamasari (2018), Siregar et al. (2018), Hartanti et al. (2019), Ramdhonah et al. (2019), Lubis et al. (2017), dan Oktaviarni (2019). Berdasarkan uraian di atas peneliti mengajukan hipotesa sebagai berikut:

\section{H2 : Profitabilitas berpengaruh positif terhadap nilai perusahaan}

\section{c. Pengaruh struktur modal terhadap nilai perusahaan}

Berdasarkan Teori pecking order Myers dan Maljuf (1984) menjelaskan bahwa struktur modal memiliki urutan prioritas yang umumnya perusahaan lebih mendahulukan pendanaan internal karena lebih murah baru pilihan terakhir melakukan pendanaan eksternal (jika diperlukan). Dalam rangka mencapai tujuan perusahaan dalam meningkatkan profitabilitas manajer perusahaan harus mengambil keputusan terkait struktur modal agar bisa mencapai nilai perusahaan yang diharapkan. Struktur modal yang berada pada titik optimal dapat diperoleh dengan melakukan kombinasi proporsi struktur modal antara ekuitas dan utang. Struktur modal yang tepat akan meningkatkan produktifitas perusahaan dan peforma perusahaan sehingga turut meningkatkan nilai perusahaan.

Penelitian Ramdhonah et al. (2019) melalui penelitiannya menyatakan struktur modal secara parsial mempunyai pengaruh positif dan signifikan terhadap nilai perusahaan. Berdasarkan penelitian tersebut diketahui keputusan terkait proporsi struktur modal akan mempengaruhi keberlangsungan operasional perusahaan. Jika suatu perusahaan layak menerima pinjaman artinya dari proses tersebut turut menjukkan perusahaan mampu memenuhi kewajibannya karena memiliki prospek yang baik kedepannya di mata pemberi pinjaman. Sejalan dengan penelitian Jihadi et al. (2021), Hirdinis (2019), dan Apriliyanti et al. (2019). Berdasarkan uraian di atas peneliti mengajukan hipotesa sebagai berikut:

\section{H3 : Struktur modal berpengaruh positif terhadap nilai perusahaan.}

\section{d. Pengaruh CSR memoderasi hubungan antara likuiditas}

Perusahaan tidak hanya bertujuan untuk memperoleh keuntungan untuk organisasinya, namun juga wajib menjalankan tanggung jawab sosial dan lingkungan (Ruroh \& Latifah, 2018). Menurut Kasmir (2017) likuiditas adalah cara mengetahui seberapa likuid suatu perusahaan. Semakin tinggi likuiditas menunjukan kesedian saldo kas yang besar. Hal ini bisa menunjukan perusahaan mampu dalam melakukan kegiatan Corporate Social Responsibility. Implementasi kegiatan-kegiatan CSR dapat dianggap sebagai upaya dan strategi tambahan perusahaan dalam menjalankan tanggung jawab sosial dan lingkungan sehingga dapat memberikan dampak positif terhadap citra perusahaan sehingga turut meningkatkan nilai perusahaan. Selanjutnya hasil penelitian Jihadi et al. (2021) mengemukakan CSR dapat memoderasi efek likuiditas pada nilai perusahaan. Penelitian tersebut menunjukkan CSR berhasil memperkuat dampak kepada investor dalam melakukan penilaian pada suatu perusahaan. Berdasarkan uraian di atas peneliti mengajukan hipotesa sebagai berikut:

\section{H4 : CSR memperkuat hubungan positif antara likuiditas dengan nilai perusahaan.}

\section{e. Pengaruh CSR memoderasi hubungan antara profitabilitas dengan nilai perusahaan}

Profitabilitas digunakan untuk mengukur kemampuan perusahaan dalam menghasilkan laba dari aktivitas operasionalnya (Kasmir, 2017). Profitabilitas perusahaan turut menunjukan prospek perusahaan yang baik kedepannya dalam berkompetisi dengan pesaing sehingga menarik investor untuk melakukan pengambilan keputusan dalam berinvestasi. Semakin tinggi profitabilitas akan memberikan tekanan kepada perusahaan untuk melaksanakan kegiatan Corporate Social Responsibility (Ruroh \& Latifah, 2018).

Penelitian Jihadi et al. (2021) menjelaskan CSR dapat memberikan efek terhadap hubungan profitabilitas dengan nilai perusahaan sebagai variabel moderasi. CSR memiliki peran penting dalam mengeneralisasi profit kerena melalui kegiatan-kegiatan CSR akan memberikan reputasi positif pada perusahaan. Hal ini membuat penjualan perusahaan menjadi naik sehingga profitabilitas ikut naik dan meningkatkan nilai perusahaan. Penelitian ini sejalan dengan penelitian Siregar et al. (2018). Berdasarkan uraian di atas peneliti mengajukan hipotesa sebagai berikut:

H5 : CSR memperkuat hubungan positif antara profitabilitas dengan nilai perusahaan.

\section{f. Pengaruh CSR memoderasi hubungan antara struktur modal}

Struktur modal adalah perbandingan antara utang dan modal (Brigham \& Houston, 2019). Jika struktur modal di kombinasikan dengan tepat antara utang dan ekuitas maka dapat meningkatkan nilai perusahaan. Struktur modal yang tinggi menunjukan adanya tingkat utang yang tinggi sehingga memungkinkan terjadinya pengawasan atas kemampuan bayar dari utang tersebut. Maka jika struktur modal tinggi akan membuat perusahaan mengurangi pengungkapan program CSR (Ruroh \& Latifah, 2018). Sebab perusahaan tidak ingin mendapatkan perhatian dan pengawasan dari pemberi utang. Oleh karena itu, perusahaan harus mempertimbangkan penerapan CSR sebagai bentuk tanggung jawab perusahaan kepada 
masyarakat dan melakukan pengambilan keputusan yang tepat terkait struktur modal sehingga berada di titik optimal dan dapat meningkatkan nilai perusahaan.

Pada penelitian Jihadi et al. (2021) CSR dapat memoderasi efek leverage yang diproksikan dengan Debt to Equity Ratio pada nilai perusahaan. Penelitian ini menjelaskan Debt to Equity Ratio digunakan untuk mengetahui proporsi struktur modal agar bisa juga mengetahui posisi kemampuan perusahaan dalam memenuhi kewajibannya jangka pendek dan jangka panjang sehingga meningkatkan kepercayaan publik dan meningkatkan nilai perusahaan Berdasarkan uraian diatas peneliti mengajukan hipotesa sebagai berikut:

\section{H6 : CSR memperkuat hubungan positif antara struktur modal dengan nilai perusahaan.}

\subsection{Variabel dan Pengukuran Variabel}

Variabel Dependen

Nilai Perusahaan

Nilai perusahaan dapat diproksikan dengan Tobin's Q (Chung \& Pruitt, 1994). Rumus Tobin's Q, Market Value Equity adalah harga saham pada akhir tahun dikali dengan outstanding share pada akhir tahun ditambah dengan debt (total utang) dibagi dengan total aset (Hartanti et al., 2019), sebagai berikut:

$$
\text { Tobin's } \mathrm{Q}=\frac{\text { MVE }+ \text { Debt }}{\text { Total } \text { Asset }}
$$

Variabel Independen

1. Likuiditas: Likuiditas diproksikan dengan rumus Current Ratio (Kasmir, 2017). Current Ratio mengukur likuiditas yang dihasilkan perusahaan berdasarkan aset lancar dibagi dengan utang lancar dengan rumus, yaitu:

$$
\mathrm{CR}=\frac{\text { Current Asset }}{\text { Current Liability }}
$$

2. Profitabilitas: Profitabilitas dapat diukur dengan rumus Return On Asset (Lita, 2018). Return On Asset dioperasionalkan dengan memperhitungkan laba bersih perusahaan dibagi dengan total aset, yaitu:

$$
\mathrm{ROA}=\frac{\text { Net Income after tax }}{\text { Total Asset }}
$$

3. Struktur Modal: Menurut Kasmir (2017) struktur modal dapat diukur dengan menggunakan Debt to Equity Ratio yaitu membandingkan antara seluruh utang dengan seluruh modal dengan rumus sebagai berikut:

$$
\text { DER }=\frac{\text { Total Debt }}{\text { Total Equity }}
$$

Variabel Moderasi

Corporate Social Responsibility (CSR): Corporate Social Responsibility diukur dengan menghitung jumlah item indikator CSR pada perusahaan i dibagi dengan 91 total indikator CSR menurut GRI G4 (Jihadi et al., 2021) sebagai berikut:

Variabel Kontrol

$$
\mathrm{CSRDI}=\frac{\Sigma x i j}{n i j}
$$

1. Growth (Pertumbuhan Perusahaan)

Menurut Hartono (2016) pertumbuhan perusahaan dapat diukur dengan cara mengukur perubahan total aset yaitu total aset periode sekarang dikurang total aset periode sebelumnya dibagi dengan total aset pada periode sebelumnya.

2. SIZE (Ukuran Perusahaan)

SIZE diukur dengan menggunakan logaritma dari total aset (Hartono, 2016).

\subsection{Model Empiris Penelitian}

Model 1:

Tobin's $Q=\beta_{0}+\beta_{1} C R_{i t}+\beta_{2}$ ROA $_{i t}+\beta_{3}$ DER $_{i t}+\beta_{4} C S R_{i t}+\beta_{5}$ Growth $_{i t}+\beta_{6}$ SIZE $_{i t}+\varepsilon_{i t}$

Keterangan: $\beta_{0}, \beta_{1}, \beta_{2}, \beta_{3}, \beta_{4}, \beta_{5}, \beta_{6}$ adalah Koefisien Variabel, Tobin's Q adalah Nilai Perusahaan, CR adalah Current Ratio (Likuiditas), ROA adalah Return On Asset (Profitabilitas), DER adalah Debt to Equity Ratio (Struktur Modal), CSR adalah Corporate Social Responsibility, Growth adalah Pertumbuhan perusahaan, SIZE adalah Ukuran perusahaan, $\varepsilon$ adalah Error, i adalah perusahaaan, dan $\mathrm{t}$ adalah tahun.

Model 2:

Tobin's $Q=\beta_{0}+\beta_{1} C R_{i t}+\beta_{2} \mathrm{ROA}_{i t}+\beta_{3} \mathrm{DER}_{i t}+\beta_{4} C S R_{i t}+\beta_{5} C R_{-} C S R+\beta_{6} \mathrm{ROA}_{-} \mathrm{CSR}_{i t}+\beta_{7} \mathrm{DER}_{-} C S R_{i t}+$ $\beta_{8}$ Growth $_{i t}+\beta_{9}$ SIZE $_{i t}+\varepsilon_{i t}$

Keterangan: $\beta_{0}, \beta_{1}, \beta_{2}, \beta_{3}, \beta_{4}, \beta_{5}, \beta_{6}, \beta_{7}, \beta_{8}, \beta_{9}$ adalah Koefisien Variabel, Tobin's Q adalah Nilai Perusahaan, CR adalah Current Ratio (Likuiditas), ROA adalah Return On Asset (Profitabilitas), DER adalah Debt to Equity Ratio (Struktur Modal), CSR adalah Corporate Social Responsibility, CR_CSR adalah Interaksi likuiditas dengan CSR, ROA_CSR adalah Interaksi profitabilitas dengan CSR, DER_CSR adalah Interaksi struktur modal dengan CSR, Growth adalah Pertumbuhan perusahaan, SIZE adalah Ukuran perusahaan, $\varepsilon$ adalah Error, i adalah perusahaaan, dan $t$ adalah tahun. 


\subsection{Metode Analisis Data}

Dalam menganalisis data peneliti menggunakan program Statistical Package for the Social Science atau SPSS. Melalui program IBM SPSS Statistic versi 25, peneliti dapat mengolah data yang memberikan Informasi dari analisis data pada beberapa pengujian, diantaranya sebagai berikut:

1. Analisis Statistik Deskriptif

Statistika deskriptif memperlihatkan gambaran Informasi mengenai variabel-variabel yang digunakan dalam penelitian (jumlah sampel, minimum, maksimum, mean, median, standar deviasi, dan lainnya) (Imam Ghozali, 2018).

\section{Asumsi Klasik}

Pengujian asumsi klasik perlu dilakukan untuk menguji model berdasarkan sampel data yang sudah ada sehingga dapat memenuhi persyaratan uji statistik sebelum dilakukan analisa model regresi. Pengujian asumsi klasik terdiri dari uji normalitas, uji multikolinearitas, uji heteroskedastisitas, dan uji autokorelasi (I Ghozali, 2020).

3. Uji Hipotesis

Pengujian hipotesis pada penelitian ini menggunakan moderated regression analysis, yaitu pengujian yang menggunakan pendekatan analisis pada regresi linear berganda dengan aplikasi khusus yang dalam persamaannya dapat memberikan dasar untuk mengontrol pengaruh variabel moderator. Variabel moderator adalah variabel yang dapat memperkuat atau memperlemah hubungan antara variabel independen dengan variabel dependen (I Ghozali, 2020). Uji Hipotesis terdiri dari uji koefisien determinasi $\left(\mathrm{R}^{2}\right)$, uji signifikansi simultan (Uji statistik $\left.\mathrm{F}\right)$, dan uji signifikansi parameter individual (Uji Statistik t).

\section{HASIL DAN PEMBAHASAN}

\subsection{Statistika Deskriptif dan Regresi}

Tabel 1. Hasil Statistika Deskriptif

\begin{tabular}{llrrrr}
\hline & N & Minimum & Maximum & Mean & Std. Deviation \\
\hline Tobin's Q & 240 & .34 & 7.51 & 1.4365 & 1.13938 \\
CR & 240 & .10 & 7.90 & 2.0896 & 1.64203 \\
ROA & 240 & -.30 & .40 & .0417 & .07717 \\
DER & 240 & -1.47 & 3.27 & .5860 & .70796 \\
CSR & 240 & .01 & .37 & .1522 & .08968 \\
Growth & 240 & -.30 & .70 & .1242 & .15658 \\
SIZE & 240 & 10.64 & 19.68 & 14.893 & 1.7466 \\
CR_CSR & 240 & .00 & 1.73 & .3173 & .33052 \\
DER_CSR & 240 & -.50 & .55 & .0882 & .12722 \\
ROA_CSR & 240 & -.06 & .07 & .0063 & .01350 \\
\hline
\end{tabular}

Berdasarkan tabel 1 hasil statistika deskriptif menjelaskan bahwa terdapat 240 data perusahaan dengan hasil interpretasi sebagai berikut: Nilai perusahaan-Tobin's Q (variabel dependen) mempunyai nilai minimum 0,34, nilai maksimum 7,51, nilai mean 1,4365, dan standar deviasi 1,13938. Likuiditas-CR (variabel independen) mempunyai nilai minimum 0,10, nilai maksimum 7,90, nilai mean 2,0896, dan standar deviasi 1,64203. Profitabilitas-ROA (variabel independen) mempunyai nilai minimum -0,30, nilai maksimum 0,40, nilai mean 0,0417, dan standar deviasi 0,07717 . Struktur Modal-DER (variabel independen) mempunyai nilai minimum -1,47, nilai maksimum 3,27, nilai mean 0,5860, dan standar deviasi 0,70796. CSR-CSRDI (variabel moderasi) mempunyai nilai minimum 0,01, nilai maksimum 0,37, nilai mean 0,1522, dan standar deviasi 0,08968. Growth (variabel kontrol) mempunyai nilai minimum -0,30, nilai maksimum 0,70, nilai mean 0,1242, dan standar deviasi 0,15658. SIZE (variabel kontrol) memiliki nilai minimum 10,64, nilai maksimum 19,68, nilai mean 14,893, dan standar deviasi 1,7466. Likuiditas dengan CSR sebagai variabel moderasiCR_CSR mempunyai nilai minimum 0,00 , nilai maksimum 1,73 , nilai mean 0,3173 , dan standar deviasi 0,33052 . Profitabilitas dengan CSR sebagai variabel moderasi-ROA_CSR mempunyai nilai minimum -0,06, nilai maksimum 0,07, nilai mean 0,0063, dan standar deviasi 0,01350. Struktur Modal dengan CSR sebagai variabel moderasi-DER_CSR mempunyai nilai minimum -0,50, nilai maksimum 0,55, nilai mean 0,0882, dan standar deviasi 0,12722 .

Tabel 2. Hasil Uji Normalitas

\begin{tabular}{lrr} 
One Sample Kolmogorov Smirnov & Unstandardized Residual \\
\hline Model 1 & Asymp. Sig. (2-tailed) & $<.001$ \\
Model 2 & Asymp. Sig. (2-tailed) & $<.001$ \\
\hline
\end{tabular}

Berdasarkan tabel 2 hasil uji normalitas model 1 menunjukan nilai residual pada kolom signifikansi 2-tailed adalah kurang dari 0,001. Hal ini berarti uji normalitas One Sample Kolmogorov Smirnov-model 1 tidak terdistribusi normal karena nilai signifikansi lebih kecil dari 0,05. Berdasarkan tabel 2 hasil uji normalitas-model 2 menunjukan nilai residual 
pada kolom signifikansi 2-tailed adalah kurang dari 0,001. Hal ini berarti uji normalitas One Sample Kolmogorov Smirnov-model 2 tidak terdistribusi normal karena nilai signifikansi lebih kecil dari 0,05.

Tabel 3. Hasil Uji Multikolinearitas

\begin{tabular}{|c|c|c|c|}
\hline \multirow[b]{2}{*}{ Mode } & & \multicolumn{2}{|c|}{ Collinearity Statistics } \\
\hline & & Tolerance & VIF \\
\hline \multirow[t]{7}{*}{1} & (Constant) & & \\
\hline & $\mathrm{CR}$ & .733 & 1.365 \\
\hline & DER & .884 & 1.131 \\
\hline & ROA & .765 & 1.307 \\
\hline & Growth & .878 & 1.139 \\
\hline & SIZE & .840 & 1.191 \\
\hline & CSR & .976 & 1.025 \\
\hline \multirow[t]{10}{*}{2} & (Constant) & & \\
\hline & $\mathrm{CR}$ & .148 & 6.750 \\
\hline & DER & .256 & 3.901 \\
\hline & ROA & .168 & 5.939 \\
\hline & Growth & .858 & 1.165 \\
\hline & SIZE & .837 & 1.194 \\
\hline & CSR & .272 & 3.681 \\
\hline & CR_CSR & .118 & 8.506 \\
\hline & DER_CSR & .226 & 4.424 \\
\hline & ROA_CSR & .167 & 5.973 \\
\hline
\end{tabular}

Pada tabel 3 hasil uji multikolinearitas-model 1 dijelaskan bahwa likuiditas $(C R)$, struktur modal (DER), profitabilitas (ROA), pertumbuhan perusahaan (Growth), ukuran perusahaan (SIZE), dan Corporate Social Responsibility (CSR) menunjukan tidak terjadi gejala multikolinearitas. Hal itu dapat dilihat dari nilai tolerance yang lebih dari $>0,10$ dan Variance Inflation Factor (VIF) yang kurang dari < 10. Pada tabel 3 hasil uji multikolinearitas-model 2 dijelaskan bahwa likuiditas $(C R)$, struktur modal (DER), profitabilitas (ROA), pertumbuhan (Growth), ukuran perusahaan (SIZE), Corporate Social Responsibility(CSR), likuiditas dengan CSR sebagai variabel moderasi (CR_CSR), struktur modal dengan CSR sebagai variabel moderasi (DER_CSR), profitabilitas dengan CSR sebagai variabel moderasi (ROA_CSR) menunjukan tidak terjadi gejala multikolinearitas. Hal itu dapat dilihat dari nilia tolerance yang lebih dari $>0,10$ dan Variance Inflation Factor (VIF) yang kurang dari $<10$.

Tabel 4. Hasil Uji Heteroskedastisitas

\begin{tabular}{llr}
\hline \multirow{2}{*}{ Model } & & Sig. \\
\hline 1 & (Constant) & .545 \\
& CR & .028 \\
& DER & $<.001$ \\
& ROA & .265 \\
& Growth & .469 \\
& SIZE & .161 \\
& CSR & .391 \\
\hline 2 & (Constant) & .842 \\
& CR & .046 \\
& DER & .007 \\
& ROA & .517 \\
& Growth & .745 \\
& SIZE & .093 \\
& CSR & .916 \\
& CR_CSR & .300 \\
& DER_CSR & .843 \\
& ROA_CSR & .162 \\
\hline
\end{tabular}

Pada tabel 4 hasil uji heteroskedastisitas-model 1 diketahui bahwa tidak mempunyai gejala heteroskedastisitas pada likuiditas $(C R)$, profitabilitas (ROA), pertumbuhan (Growth), ukuran perusahaan (SIZE), Corporate Social Responsibility (CSR) dikarenakan nilai signifikansi (sig) lebih dari >0,05. Namun, mempunyai gejala heteroskedastisitas pada struktur modal (DER) dikarenakan nilai signifikansi kurang dari 0,001<0,05. 
Pada tabel 4 hasil uji heteroskedastisitas-model 2 diketahui bahwa tidak mempunyai gejala heteroskedastisitas pada likuiditas (CR), profitabilitas (ROA), pertumbuhan (Growth), ukuran perusahaan (SIZE), Corporate Social Responsibility (CSR), likuiditas dengan CSR sebagai variabel moderasi (CR_CSR), struktur modal dengan CSR sebagai variabel moderasi (DER_CSR), dan profitabilitas dengan CSR sebagai variabel moderasi (ROA_CSR) dikarenakan nilai signifikansi lebih dari $>0,05$. Namun, mempunyai gejala heteroskedastisitas pada struktur modal (DER) dikarenakan nilai signifikansi (sig) 0,007 kurang dari <0,05.

Tabel 5. Hasil Uji Autokorelasi

\begin{tabular}{lccrr}
\hline Model & DW & \multicolumn{1}{c}{ DL } & \multicolumn{1}{c}{ DU } & \multicolumn{1}{c}{ 4-DU } \\
\hline 1 & 1.494 & 1,746 & 1,831 & 2,169 \\
2 & 1.514 & 1,720 & 1,857 & 2,143 \\
\hline
\end{tabular}

Pada tabel 5 hasil uji autokorelasi (DW)-model 1 dengan nilai $\mathrm{N}=240$ dan $\mathrm{K}=6$ yang terdiri dari variabel independen, moderasi, dan kontrol memiliki nilai Durbin Watson sebesar 1,494. Berdasarkan tabel DW sig 5\% diperoleh nilai dl 1,746 dan du 1,831. Pengukuran yang sesuai adalah $0<\mathrm{d}<\mathrm{dl}$ yaitu $0<1,494<1,746$ maka tidak mempunyai autokorelasi positif. Pada tabel 5 hasil uji autokorelasi (DW)-model 2 dengan nilai $\mathrm{N}=240$ dan $\mathrm{K}=9$ yang terdiri dari variabel independen, dependen, moderasi, dan control memiliki nilai Durbin Watson sebesar 1,514. Berdasarkan tabel DW sig 5\% diperoleh nilai dl 1,720 dan du 1,857. Pengukuran yang sesuai adalah $0<\mathrm{d}<\mathrm{dl}$ yaitu $0<1,514<1,720 \mathrm{maka}$ tidak mempunyai autokorelasi positif.

Tabel 6. Hasil Uji Koefisien Determinasi (Adj. R Square)

\begin{tabular}{lrrrr}
\hline Model & R & R Square & Adjusted R Square & $\begin{array}{c}\text { Std. Error of the } \\
\text { Estimate }\end{array}$ \\
\hline 1 & $.560^{\mathrm{a}}$ & .314 & .296 & .95572 \\
2 & $.570^{\mathrm{a}}$ & .325 & .298 & .95440 \\
\hline
\end{tabular}

Hasil uji koefisien determinasi (Adj. $R$ Square) berdasarkan tabel 6 hasil uji koefisien determinasi (Adj. $R$ Square) -model 1 dijelaskan bahwa likuiditas $(C R)$, profitabilitas (ROA), struktur modal (DER), pertumbuhan (Growth), ukuran perusahaan (SIZE), dan Corporate Social Responsibility (CSR) berpengaruh secara simultan terhadap nilai perusahaan (Tobin's Q) sebesar 29,6\% sedangkan 70,4\% dijelaskan dengan variabel lain yang tidak digunakan pada model penelitian ini.

Hasil uji koefisien determinasi (Adj. $R$ Square) berdasarkan tabel 4.13 hasil uji koefisien determinasi (Adj. $R$ Square) -model 2 dijelaskan bahwa likuiditas (CR), struktur modal (DER), profitabilitas (ROA), pertumbuhan (Growth), ukuran perusahaan (SIZE), Corporate Social Responsibility(CSR), likuiditas dengan CSR sebagai variabel moderasi (CR_CSR), struktur modal dengan CSR sebagai variabel moderasi (DER_CSR), dan profitabilitas dengan CSR sebagai variabel moderasi (ROA_CSR) mempunyai pengaruh secara simultan terhadap nilai perusahaan (Tobin's Q) sebesar $29,8 \%$ sedangkan 70,2\% dijelaskan dengan variabel-variabel lain yang tidak digunakan pada model penelitian ini.

Tabel 7. Hasil Uji Pengaruh Stimultan (Uji Statistik F)

\begin{tabular}{llrrrrr}
\hline Model & & Sum of Squares & df & Mean Square & F & \multicolumn{1}{c}{ Sig. } \\
\hline 1 & Regression & 97.445 & 6 & 16.241 & 17.781 & $<.001^{\mathrm{b}}$ \\
& Residual & 212.821 & 233 & .913 & & \\
& Total & 310.266 & 239 & & & \\
2 & Regression & 100.766 & 9 & 11.196 & 12.292 & $<.001^{\mathrm{b}}$ \\
& Residual & 209.501 & 230 & .911 & & \\
& Total & 310.266 & 239 & & & \\
\hline
\end{tabular}

Berdasarkan pengujian stimultan diperoleh hasil tabel 7 hasil uji stimultan (Uji Statistik F)-Model 1 yang menjelaskan bahwa nilai $F$ value sebesar 17.781 dan nilai signifikansi sebesar $<0,001$ yang berarti memiliki signifikansi pada alpha $1 \%$. Hal ini menunjukkan secara bersama-sama seluruh variabel independen likuiditas $(C R)$, profitabilitas (ROA), dan struktur modal (DER) mempengaruhi nilai perusahaan yang diproksikan menggunakan Tobin's Q. Berdasarkan pengujian stimultan diperoleh hasil tabel 7 hasil uji stimultan (Uji Statistik F)-Model 2 yang menjelaskan bahwa nilai $\mathrm{F}$ value sebesar 12.292 dan nilai signifikansi sebesar $<0,001$ yang berarti memiliki signifikansi pada alpha 1\%. Hal ini menunjukkan secara bersama-sama seluruh variabel independen), likuiditas dengan CSR sebagai variabel moderasi (CR_CSR), struktur modal dengan CSR sebagai variabel moderasi (DER_CSR), dan profitabilitas dengan CSR sebagai variabel moderasi (ROA_CSR) mempengaruhi nilai perusahaan yang diproksikan menggunakan Tobin's Q.

Tabel 8. Hasil Uji Signifikansi Parameter Individual (Uji t)

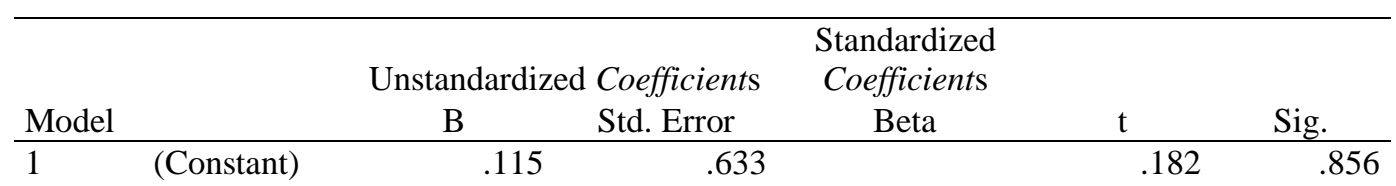




\begin{tabular}{|c|c|c|c|c|c|c|}
\hline \multirow{3}{*}{ Model } & & \multicolumn{5}{|c|}{$\begin{array}{c}\text { Standardized } \\
\text { Coefficients }\end{array}$} \\
\hline & & $\mathrm{B}$ & Std. Error & Beta & $\mathrm{t}$ & Sig. \\
\hline & $\mathrm{CR}$ & .010 & .044 & .014 & .216 & .829 \\
\hline & DER & -.708 & .093 & -.440 & -7.627 & $<.001$ \\
\hline & ROA & 3.786 & .916 & .256 & 4.134 & $<.001$ \\
\hline & Growth & .281 & .421 & .039 & .666 & .506 \\
\hline & SIZE & .110 & .039 & .169 & 2.858 & .005 \\
\hline & CSR & -.788 & .698 & -.062 & -1.130 & .260 \\
\hline 2 & (Constant) & .189 & .650 & & .290 & .772 \\
\hline & $\mathrm{CR}$ & .050 & .098 & .072 & .510 & .610 \\
\hline & DER & -.942 & .172 & -.586 & -5.472 & $<.001$ \\
\hline & ROA & 2.045 & 1.950 & .138 & 1.049 & .295 \\
\hline & Growth & .161 & .426 & .022 & .379 & .705 \\
\hline & SIZE & .114 & .039 & .175 & 2.958 & .003 \\
\hline & CSR & -1.715 & 1.321 & -.135 & -1.299 & .195 \\
\hline & CR_CSR & -.224 & .545 & -.065 & -.410 & .682 \\
\hline & DER_CSR & 1.677 & 1.021 & .187 & 1.643 & .102 \\
\hline & ROA_CSR & 11.666 & 11.175 & .138 & 1.044 & .298 \\
\hline
\end{tabular}

Berdasarkan pada tabel 8 hasil uji signifikansi parameter individual (uji statistik t)-model 1 dapat dilakukan interpretasi sebagai berikut : Likuiditas yang diproksikan dengan Current Ratio mempunyai nilai coefficient 0.010 dan nilai signifikansi 0,829 dibagi dua menjadi 0,415 dikarenakan hipotesa memiliki arah (one-tailed). Nilai coefficient positif menunjukkan bahwa likuiditas memiliki arah positif terhadap nilai perusahaan. Tingkat signifikansi menunjukkan likuiditas tidak berpengaruh signifikan terhadap alpha 10\% maka bisa disimpulkan secara parsial likuiditas memiliki arah positif namun tidak berpengaruh signifikan terhadap nilai perusahaan. Struktur Modal yang diproksikan dengan Debt to Equity Ratio mempunyai nilai coefficient -0.708 dan nilai signifikansi $<0,001$ dibagi dua menjadi 0,000 dikarenakan hipotesa memiliki arah (one-tailed). Nilai coefficient negatif menunjukkan bahwa struktur modal memiliki arah negatif terhadap nilai perusahaan. Tingkat signifikansi menunjukkan struktur modal berpengaruh signifikan terhadap alpha $1 \%$ maka bisa disimpulkan secara parsial struktur modal memiliki arah negatif namun berpengaruh signifikan terhadap nilai perusahaan. Profitabilitas yang diproksikan dengan Return On Asset mempunyai nilai coefficient 3.786 dan nilai signifikansi <0,001 dibagi dua menjadi 0,000 dikarenakan hipotesa memiliki arah (one-tailed). Nilai coefficient positif menunjukkan bahwa profitabilitas memiliki arah positif terhadap nilai perusahaan. Tingkat signifikansi menunjukkan profitabilitas berpengaruh signifikan terhadap alpha 1\% maka bisa disimpulkan secara parsial profitabilitas memiliki arah positif dan berpengaruh signifikan terhadap nilai perusahaan.

Berdasarkan pada tabel 8 hasil uji signifikansi parameter individual (uji statistik t)-model 2 dapat dilakukan interpretasi sebagai berikut : Likuiditas dengan CSR sebagai variabel moderasi (CR_CSR), diproksikan dengan Current Ratio*CSRDI mempunyai nilai coefficient -0.224 dan nilai signifikansi 0,682 dibagi dua menjadi 0,341 dikarenakan hipotesa memiliki arah (one-tailed). Nilai coefficient negatif menunjukkan bahwa CSR sebagai variabel moderasi memiliki arah negatif terhadap hubungan antara likuiditas dan nilai perusahaan. Tingkat signifikansi menunjukkan likuiditas dengan CSR sebagai variabel moderasi tidak berpengaruh signifikan terhadap alpha 10\% maka bisa disimpulkan CSR sebagai variabel moderasi memperlemah hubungan negatif antara likuiditas dengan nilai perusahaan. Struktur modal dengan CSR sebagai variabel moderasi (DER_CSR), diproksikan dengan Debt to Equity Ratio*CSRDI mempunyai nilai coefficient 1.677 dan nilai signifikansi 0,102 dibagi dua menjadi 0,051 dikarenakan hipotesa memiliki arah (one-tailed). Nilai coefficient positif menunjukkan bahwa CSR sebagai variabel moderasi memiliki arah positif terhadap hubungan antara struktur modal dan nilai perusahaan. Tingkat signifikansi menunjukkan struktur modal dengan CSR sebagai variabel moderasi berpengaruh signifikan terhadap alpha 10\% maka bisa disimpulkan CSR sebagai variabel moderasi memperkuat hubungan positif antara struktur modal dengan nilai perusahaan. Profitabilitas dengan CSR sebagai variabel moderasi (ROA_CSR), diproksikan dengan Return On Asset*CSRDI mempunyai nilai coefficient 11.666 dan nilai signifikansi 0,298 dibagi dua menjadi 0,149 dikarenakan hipotesa memiliki arah (one-tailed). Nilai coefficient positif menunjukkan bahwa CSR sebagai variabel moderasi memiliki arah positif terhadap hubungan antara profitabilitas dan nilai perusahaan. Tingkat signifikansi menunjukkan profitabilitas dengan CSR sebagai variabel moderasi tidak berpengaruh signifikan terhadap alpha $10 \%$ maka bisa disimpulkan CSR sebagai variabel moderasi memperlemah hubungan positif antara profitabilitas dengan nilai perusahaan.

\subsection{Pembahasan}

\section{a. Likuiditas berpengaruh positif dan tidak signifikan terhadap Nilai Perusahaan}

Hasil pengujian hipotesa pengaruh likuiditas terhadap nilai perusahaan (H1) berdasarkan tabel 8 menjelaskan bahwa nilai coefficient memiliki arah positif. Hal ini menunjukkan semakin tinggi nilai likuiditas maka semakin tinggi nilai perusahaan. Nilai likuiditas perusahaan yang tinggi menunjukan banyaknya kas yang tersedia pada perusahaan sehingga menunjukkan adanya kas yang kurang efisiensi dalam pengelolaan kas/setara kas. 
Hal tersebut akan memberikan sinyal negatif kepada investor sehingga nilai likuiditas tidak mempengaruhi nilai perusahaan. Selain itu likuiditas hanya menunjukkan kemampuan perusahaan dalam melunasi hutang jangka pendek saja sehingga kebanyakan investor tidak menjadikan likuiditas sebagai faktor utama dalam melakukan pengambilan keputusan untuk berinvestasi. Hasil penelitian ini menjelaskan likuiditas yang diukur dengan menggunakan rumus Current Ratio memiliki arah positif namun tidak berpengaruh secara signifikan terhadap nilai perusahaan sehingga hipotesa 1 ditolak. Hasil penelitian ini sejalan dengan penelitian Lubis (2017) yang mengatakan bahwa likuiditas memiliki hubungan positif namun tidak berpengaruh signifikan pada nilai perusahaan.

\section{b. Profitabilitas berpengaruh positif dan signifikan terhadap Nilai Perusahaan}

Hasil pengujian hipotesa pengaruh profitabilitas terhadap nilai perusahaan $(\mathrm{H} 2)$ berdasarkan tabel 8 menjelaskan bahwa nilai coefficient memiliki arah positif. Hal ini menunjukkan semakin tinggi nilai profitabilitas maka semakin tinggi nilai perusahaan. Pada saat perusahaan memperoleh keuntungan maka investor akan mendapatkan sinyal positif yang menujukkan perusahaan memiliki kinerja yang baik. Sinyal positif tersebut mempengaruhi keputusan investor pada saat menilai suatu perusahaan. Profitabilitas dapat meningkatkan potensi investor dalam melakukan investasi pada perusahaan tersebut. Selain itu, berdasarkan kenaikan profitabilitas akan meningkatkan laba yang diterima oleh investor sehingga dapat meningkatkan permintaan saham dan akan membawa dampak positif pada nilai perusahaan. Hasil penelitian ini menjelaskan profitabilitas yang diukur dengan menggunakan rumus Return On Asset memiliki hubungan positif dan berpengaruh secara signifikan terhadap nilai perusahaan sehingga hipotesa 2 diterima.

Hasil penelitian ini sesuai dengan penelitian Hartanti et al. (2019) yang menunjukan profitabilitas memiliki pengaruh positif dan signifikan terhadap nilai perusahaan karena semakin tinggi profitabilitas perusahaan atas kegiatan operasionalnya akan menunjukan prospek perusahaan yang baik dimasa depan dan turut meningkatkan nilai perusahaan. Penelitian Jihadi et al. (2021), Mufidah dan Purnamasari (2018), Siregar et al. (2018), Ramdhonah et al. (2019), Lubis et al. (2017), Dhani dan Utama (2017), dan Oktaviarni (2019) juga menjelaskan hasil bahwa profitabilitas memiliki pengaruh positif dan signifikan terhadap nilai perusahaan.

\section{c. Struktur Modal berpengaruh negatif dan signifikan terhadap Nilai Perusahaan}

Hasil pengujian hipotesa pengaruh struktur modal terhadap nilai perusahaan (H3) berdasarkan tabel 8 menjelaskan bahwa nilai coefficient memiliki arah negatif. Hal ini menunjukkan semakin tinggi nilai struktur modal maka semakin rendah nilai perusahaan. Berdasarkan teori pecking order dijelaskan bahwa struktur modal memiliki urutan prioritas yang umumnya perusahaan lebih mendahulukan pendanaan internal karena lebih murah sehingga pendanaan eksternal menjadi pilihan terakhir (jika diperlukan). Maka manajer perusahaan harus mengambil keputusan terkait struktur modal agar bisa mencapai nilai perusahaan yang diharapkan. Sebab proporsi struktur modal yang optimal dapat mengurangi biaya ratarata modal sehingga meningkatkan profitabilitas yang turut meningkatkan nilai perusahaan.

Hasil penelitian ini menjelaskan struktur modal yang diukur dengan menggunakan rumus Debt to Equity Ratio berpengaruh signifikan namun memiliki arah negatif terhadap nilai perusahaan sehingga hipotesa 3 ditolak karena pengajuan pada hipotesa 3 yaitu memiliki hubungan positif. Hasil pada penelitian ini sesuai dengan penelitian Sukmawardini dan Ardiansari (2018) yang memperoleh hasil bahwa struktur modal memiliki hubungan negatif namun signifikan terhadap nilai signifikan.

\section{d. CSR memperlemah hubungan negatif antara likuiditas dengan nilai perusahaan}

Hasil pengujian hipotesa pengaruh CSR terhadap hubungan antara likuiditas dengan nilai perusahaan (H4) berdasarkan tabel 8 menjelaskan bahwa nilai coefficient memiliki arah negatif. Hal ini menunjukan semakin tinggi nilai likuiditas yang di moderasi dengan CSR maka semakin rendah nilai perusahaan. Nilai likuiditas pada perusahaan menunjukan banyaknya dana yang tersedia pada suatu perusahaan maka kas tersebut juga dapat digunakan untuk melaksanakan kegiatan CSR. Hal ini juga menunjukkan bahwa investor tidak mempertimbangkan likuiditas yang dimoderasi dengan CSR dalam mempengaruhi keputusan investor untuk berinvestasi pada suatu perusahaan.

Hasil penelitian ini menjelaskan bahwa CSR memiliki hubungan negatif dan memperlemah hubungan antara likuiditas dengan nilai perusahaan sehingga hipotesa 4 ditolak. Hasil penelitian ini tidak sejalan dengan penelitian Jihadi et al. (2021) yang menjelaskan bahwa CSR memperkuat hubungan negatif antara likuiditas dengan nilai perusahaan sebagai variabel moderasi. Hasil ini mungkin terjadi dikarenakan perusahaan-perusahaan pada industri konsumen non primer tidak melakukan pengungkapan CSR yang sesuai dengan pedoman GRI versi G4.

\section{e. CSR memperlemah hubungan positif antara profitabilitas dengan nilai perusahaan}

Hasil pengujian hipotesa pengaruh CSR terhadap hubungan antara profitabilitas dengan nilai perusahaan (H5) berdasarkan tabel 8 menjelaskan bahwa nilai coefficient mempunyai arah positif. Hal ini menunjukkan semakin tinggi nilai profitabilitas yang di moderasi dengan CSR maka semakin tinggi nilai perusahaan. Namun, semakin tinggi nilai profitabilitas yang dimoderasi dengan CSR tidak mempengaruhi nilai perusahaan. Hal ini dikarenakan semakin tinggi keuntungan suatu perusahaan sejalan dengan meningkatnya tanggung jawab perusahaan dari sisi sosial dan lingkungan yang ditunjukkan dengan mengimplementasikan CSR. Oleh karena itu, CSR dianggap sebagai hal yang wajib dilaksanakan setiap perusahaan dan dapat menurunkan profitabilitas atas biaya-biaya yang dikeluarkan dari pelaksanaan kegiatan CSR sehingga investor tidak melakukan pengambilan keputusan berinvestasi pada suatu perusahaan hanya dengan mempertimbangkan CSR. Hasil penelitian ini menjelaskan bahwa CSR memiliki hubungan positif dan 
memperlemah hubungan antara profitabilitas dengan nilai perusahaan sehingga hipotesa 5 ditolak. Hasil penelitian ini tidak sejalan dengan penelitian Siregar (2018) yang menjelaskan CSR memperkuat hubungan positif antara profitabilitas yang diproksikan dengan ROA terhadap nilai perusahaan.

\section{f. CSR memperkuat hubungan positif antara struktur modal dengan nilai perusahaan}

Hasil pengujian hipotesa pengaruh CSR terhadap hubungan antara struktur modal dengan nilai perusahaan (H6) berdasarkan tabel 8 menjelaskan bahwa nilai coefficient memiliki arah positif. Hal ini berarti semakin tinggi nilai struktur modal yang di moderasi dengan CSR maka semakin tinggi nilai perusahaan. Perusahaan yang memiliki nilai DER tinggi menunjukan bahwa proporsi struktur modal dari pendanaan pihak eksternal lebih besar dibandingkan pendanaan internal sehingga perusahaan memiliki kewajiban yang lebih besar untuk melakukan pengungkapan CSR karena diawasi oleh debt holders. Berdasarkan tingginya nilai hutang juga dapat menunjukkan bahwa perusahaan memiliki kemampuan untuk membayar kewajibannya berdasarkan kondisi-kondisi yang ditentukan oleh pemberi pinjaman sehingga mempengaruhi kepercayaan investor dalam berinvestasi yang turut meningkaktkan nilai perusahaan. Hasil penelitian ini menjelaskan bahwa CSR memiliki hubungan positif dan memperkuat hubungan antara struktur modal dengan nilai perusahaan sehingga hipotesa 6 diterima. Hasil penelitian ini sejalan dengan penelitian Jihadi et al. (2021) yang menjelaskan bahwa CSR dapat memperkuat hubungan positif antara struktur modal dengan nilai perusahaan.

\section{KESIMPULAN}

Pada penelitian "Likuiditas, profitabilitas, dan struktur modal terhadap nilai perusahaan dengan variabel moderasi CSR" bertujuan untuk menguji pengaruh likuiditas yang diukur dengan Current Ratio, profitabilitas yang diukur dengan return on asset, dan struktur modal yang diukur dengan debt to equity ratio terhadap nilai perusahaan yang diukur dengan Tobin's Q dengan variabel moderasi CSR yang diukur dengan CSRDI. Berdasarkan pengujian yang telah dilaksanakan maka diperoleh hasil kesimpulan sebagai berikut: likuiditas memiliki arah positif namun tidak berpengaruh signifikan terhadap nilai perusahaan, profitabilitas memiliki arah positif dan berpengaruh signifikan terhadap nilai perusahaan, struktur modal memiliki arah negatif namun berpengaruh signifikan terhadap nilai perusahaan, CSR sebagai variabel moderasi memperlemah hubungan negatif antara likuiditas dengan nilai perusahaan, CSR sebagai variabel moderasi memperlemah hubungan positif antara profitabilitas dengan nilai perusahaan, dan CSR sebagai variabel moderasi memperkuat hubungan positif antara struktur modal dengan nilai perusahaan.

\section{UCAPAN TERIMAKASIH}

Terima kasih disampaikan kepada pihak-pihak yang telah mendukung terlaksananya penelitian ini.

\section{REFERENCES}

Apriliyanti, V., Hermi, H., \& Herawaty, V. (2019). Pengaruh Kebijakan Hutang, Kebijakan Dividen, Profitabilitas, Pertumbuhan Penjualan dan Kesempatan Investasi terhadap Nilai Perusahaan dengan Ukuran Perusahaan sebagai Variabel Moderasi. Jurnal Magister Akuntansi Trisakti, 6(2), 201. https://doi.org/10.25105/jmat.v6i2.5558

Brigham, E. F., \& Houston, J. F. (2019). Fundamentals of Financial Management 15 Edition. Cengage Learning.

Chung, K. H., \& Pruitt, S. W. (1994). Approximation of Tobin's Q. Financial Management, 23(3), 70-74.

Dhani, I. P., \& Utama, A. A. G. S. (2017). Pengaruh Pertumbuhan Perusahaan, Struktur Modal, Dan Profitabilitas Terhadap Nilai Perusahaan. Jurnal Riset Akuntansi Dan Bisnis Airlangga, 2 No 1, 135-148.

Ghozali, I. (2020). Ekonometrika: Teori, Konsep dan Aplikasi dengan IBM SPSS 24. Badan Penerbit Universitas Diponegoro Semarang.

Ghozali, Imam. (2018). Aplikasi Analisis Multivariate dengan Program IBM SPSS 25 (9th ed.). Badan Penerbit Universitas Diponegoro Semarang.

Hartanti, R., Yulandani, F., \& Riandi, M. R. (2019). The Effect of Profitability, Capital Structure, and Implementation of Corporate Governance Mechanism on Firm Value. Jurnal Akuntansi Trisakti, 6(1), 83. https://doi.org/10.25105/jat.v6i1.4872

Hartono, J. (2016). Teori Portofolio dan Analisis Investasi (10th ed.). BPFE.

Hirdinis, M. (2019). Capital Structure and Firm Size on Firm Value Moderated by Profitability. International Journal of Economics and Business Administration, 7(1), 174-191. https://doi.org/10.35808/ijeba/204

Jariah, A. (2016). Likuiditas, Leverage, Profitabilitas Pengaruhnya terhadap Nilai Perusahaan Manufaktur di Indonesia melalui Kebijakan Deviden. In Riset Akuntansi dan Keuangan Indonesia (Vol. 1, Issue 2).

Jihadi, M., Vilantika, E., Hashemi, S. M., Arifin, Z., Bachtiar, Y., \& Sholichah, F. (2021). The Effect of Liquidity, Leverage, and Profitability on Firm Value: Empirical Evidence from Indonesia. Journal of Asian Finance, Economics and Business, 8(3), 423431. https://doi.org/10.13106/jafeb.2021.vol8.no3.0423

Kartini, D. (2020). Corporate Social Responsibility. PT. Refika Aditama.

Kasmir. (2017). Analisis Laporan Keuangan (10th ed.). PT RAJAGRAFINDO PERSADA.

Lita, E. (2018). Reading Financial Report for Dummies (3rd ed.). John Wiley \& Sons Inc.

Lubis, I. L., Sinaga, B. M., \& Sasongko, H. (2017). Effect of Profitability,Capital Structures, and Liquidity to the Value of the Company. Jurnal Aplikasi Bisnis Dan Manajemen, 3(3), 458-465.

Majluf, N. S., \& Myers, S. C. (1984). Corporate Financing and Investment Decisions When Firms Have Information That Investors Do Not Have. 13, 187-221.

Marantika, A. (2012). Nilai Perusahaan (Firm Value) Konsep dan Implikasi. Aura. 
Mufidah, N., \& Purnamasari, P. E. (2018). Pengaruh Profitabilitas terhadap Nilai Perusahaan dengan Pengungkapan Corporate Social Responsibility dan Good Corporate Governance sebagai Variabel Moderating. El Dinar, 6(1).

Oktaviarni, F. (2019). Pengaruh Profitabilitas, Likuiditas, Leverage, Kebijakan Dividen, dan Ukuran Perusahaan terhadap Nilai Perusahaan. Jurnal Akuntansi, 9(1), 1-16. https://doi.org/10.33369/j.akuntansi.9.1.1-16

Ramdhonah, Z., Solikin, I., \& Sari, M. (2019). Pengaruh Struktur Modal, Ukuran Perusahaan, Pertumbuhan Perusahaan, dan Profitabilitas terhadap Nilai Perusahaan (Studi Empiris pada Perusahaan Sektor Pertambangan yang Terdaftar di Bursa Efek Indonesia Tahun 2011-2017). Jurnal Riset Akuntansi Dan Keuangan, 7(1), 67-82. https://doi.org/10.17509/jrak.v7i1.15117

Ruroh, I. N., \& Latifah, S. W. (2018). Pengaruh Profitabilitas, Leverage, Ukuran Perusahaan dan Risk Minimization terhadap Pengungkapan Corporate Social Responsibility (CSR). Jurnal Akademi Akuntansi, 1 No 1, 42-53.

Siregar, I. F., Roekhudin, R., \& Purwanti, L. (2018). Firm Value Predictor and the Role of Corporate Social Responsibility. Jurnal Keuangan Dan Perbankan, 22(3). https://doi.org/10.26905/jkdp.v22i3.1804

Sukmawardini, D., \& Ardiansari, A. (2018). The Influence of Institutional Ownership. Profitability, Liquidity, Dividend Policy, Debt Policy on Firm Value. Management Analysis Journal, 7(2), 212-222.

WorldBankGroup. (2021). GDP growth (annual \%) - Indonesia. WorldBankGroup. https://data.worldbank.org/indicator/NY.GDP.MKTP.KD.ZG?end=2020\&locations=ID\&name_desc=false \&start=2010\&view= chart 